\title{
Application of geo-spatial technology in schistosomiasis modelling in Africa: a review
}

\author{
Tawanda Manyangadze, ${ }^{1}$ Moses John Chimbari, ${ }^{1}$ Michael Gebreslasie, ${ }^{2}$ Samson Mukaratirwa ${ }^{3}$ \\ ${ }^{1}$ School of Nursing and Public Health, Department of Public Health Medicine, University of KwaZulu-Natal, \\ Durban; ${ }^{2}$ School of Agriculture, Earth and Environmental Sciences, University of KwaZulu-Natal, Durban; \\ ${ }^{3}$ School of Life Sciences, University of KwaZulu-Natal, Durban, South Africa
}

\begin{abstract}
Schistosomiasis continues to impact socio-economic development negatively in sub-Saharan Africa. The advent of spatial technologies, including geographic information systems (GIS), Earth observation (E0) and global positioning systems (GPS) assist modelling efforts. However, there is increasing concern regarding the accuracy and precision of the current spatial models. This paper reviews the literature regarding the progress and challenges in the development and utilization of spatial technology with special reference to predictive models for schistosomiasis in Africa. Peer-reviewed papers identified through a PubMed search using the following keywords: geo-spatial analysis $\mathrm{OR}$ remote sensing $\mathrm{OR}$ modelling $\mathrm{OR}$ earth observation $\mathrm{OR}$ geographic information systems $\mathrm{OR}$ prediction OR mapping AND schistosomiasis AND Africa were used. Statistical uncertainty, low spatial and temporal resolution satellite data and poor validation were identified as some of the factors that compromise the precision and accuracy of the existing predictive models. The need for high spatial resolution of remote sens-
\end{abstract}

Correspondence: Tawanda Manyangadze, School of Nursing and Public Health, Department of Public Health Medicine, University of KwaZulu-Natal, Durban, South Africa.

Tel. +27.78.4090822 - Fax: +27.31.2601824.

E-mail: manyangadze.tawanda@gmail.com

Key words: Earth observation; Geographic information systems; Geo-spatial technologies; Schistosomiasis modelling; Africa.

Acknowledgments: the research has been supported by College of Health Sciences scholarship program at University of KwaZulu-Natal and Malaria and Bilharzia in Southern Africa (MABISA) project funded by WHO Special Programme for Research and Training in Tropical Diseases (TDR) and the Canadian International Development Research Centre (IDRC).Many thanks to MABISA team members especially in South Africa: Owen Rubaba, White Soko and Prestage Murima for their continuous support.

Received for publication: 4 February 2015.

Accepted for publication: 10 April 2015.

CCopyright T. Manyangadze et al., 2015

Licensee PAGEPress, Italy

Geospatial Health 2015; 10:326

doi:10.4081/gh.2015.326

This article is distributed under the terms of the Creative Commons Attribution Noncommercial License (by-nc 3.0) which permits any noncommercial use, distribution, and reproduction in any medium, provided the original author(s) and source are credited. ing data in conjunction with ancillary data viz. ground-measured climatic and environmental information, local presence/absence intermediate host snail surveys as well as prevalence and intensity of human infection for model calibration and validation are discussed. The importance of a multidisciplinary approach in developing robust, spatial data capturing, modelling techniques and products applicable in epidemiology is highlighted.

\section{Introduction}

Schistosomiasis, caused by Schistosoma haematobium and S. mansoni, is a disease that mainly affects under-resourced communities and is often not prioritized in national budgets in sub-Saharan Africa (WHO, 2014). Approximately 600 million people are at risk worldwide and over 200 million people are infected (Chitsulo et al., 2000; King, 2009). The Schistosomiasis Control Initiative (SCI) works with national governments in sub-Saharan Africa to control and eliminate schistosomiasis. A recent national schistosomiasis survey contributed to the development of the schistosomiasis and soil transmitted helminths (STH) National Control Program in Zimbabwe that involves mass drug administration (MDA) (Midzi et al., 2014). Despite the efforts to control the disease in sub-Saharan Africa, 80-95\% of the global, total number of schistosomiasis infected individuals still live in Africa (WHO, 2002; Steinmann et al., 2006; Utzinger et al., 2009; Hurlimann et al., 2011). It is estimated that about 200000 deaths per year are caused by schistosomiasis in sub-Sahara Africa (WHO, 2014). The distribution of schistosomiasis is reflected by the geographical distribution of the intermediate host snail species (Despommier et al., 1994), which is a well-known phenomenon but difficult to predict and monitor. It is envisaged that knowing the drivers of the current distribution of schistosomiasis could improve our understanding on how climate and environmental changes may influence the distribution of schistosomiasis in the future. This is critical to effectively and efficiently manage surveillance, control and prevention of the disease (Stensgaard et al., 2005). King et al. (2006) emphasize that the next generation of schistosomiasis control will be optimized using new monitoring tools and effective transmission containment. Enhanced by the advancements in statistical ecological modelling, spatial technologies which provide spatial data and tools for spatial analysis and predictive modelling have opened a new way for developing such monitoring tools. The development of geo-spatial technology such as geographical information systems (GIS) and global positioning system (GPS) have facilitated the integration of Earth observation (E0) driven environmental parameters with health data for the development of disease surveillance and control models (Beck et al., 2000). GIS applications in public health include the estimation of spatial variation of disease, determination of risk factors of disease, and improved deliv- 
ery of health services (Tanser et al., 2003). This review looks at the progress and challenges in the application of spatial technologies in mapping and modelling schistosomiasis in Africa. It was inspired by the works of Brooker et al. (2002a) and Brooker (2007) and Simoonga et al. (2009), who published detailed reviews of the past developments and use of GIS and remote sensing in schistosomiasis mapping and modelling in Africa. The potential future research priorities with emphasis on application of spatial technology in schistosomiasis modelling at local levels in Africa are discussed.

\section{Selection criteria for the literature search under- taken}

This review is based on a systematic search for relevant literature in the PubMed electronic search engine (http:/www.ncbi.nlm.nih.gov/ pubmed) following the method used by Simoonga et al. (2009). This search considered the studies using geo-spatial technologies for schistosomiasis prediction, modelling and mapping in Africa based on the following combination of terms and Boolean operations: geo-spatial analysis $\mathrm{OR}$ remote sensing $\mathrm{OR}$ earth observation $\mathrm{OR}$ geographic information systems OR prediction OR mapping OR modelling AND schistosomiasis AND Africa. Any literature which did not satisfy these criteria was excluded. The snowballing technique was used to obtain more literature based on the bibliography or reference list of previous reviews obtained by the search strategy described above. Literature on schistosomiasis without the element of geo-spatial analysis were used to strengthen the discussion and understanding why geo-spatial technology has been and/or can be used to understand the schistosomiasis transmission. The relevant literature was used to determine the levels of appreciation and use of geospatial technology in schistosomiasis modelling and/or mapping by extending the yearly publication graph by Simoonga et al. (2009). These authors accessed the PubMed database in early 2009 and gave a snapshot of the number of publications on GIS and remote sensing applications used with reference to schistosomiasis in Africa between 1996 and 2008. In this review, we extended the snapshot up to 2013 using the methodology mentioned above.

\section{Search results}

The search for literature conducted for the period 2009 - 2013 revealed 59 hits of which 36 were considered relevant. The relevant publications (36) were further categorized by year of publication and combined with Simoonga et al. (2009) results for the period $1996-2008$ as presented in Figure 1. The annual number of publications on remote sensing and GIS with application to schistosomiasis in Africa has generally increased over the years as shown in Figure 1. This indicates the increased appreciation and usefulness of geospatial technology for schistosomiasis control and management through mapping, modelling or prediction. The key publications from 2009 to 2013 and 2 from 2008 which were not captured by Simoonga et al. (2009) as well as one for 2014 were categorized into the following three groups: modelling intermediate snail hosts (Table 1), modelling schistosomiasis (Table 2) and those modelling co-infection or co-endemicity of schistosomiasis and STHs (Table 3). The subsequent sections give a detailed discussion based on these publications as well as those mentioned elsewhere for example by Simoonga et al. (2009).

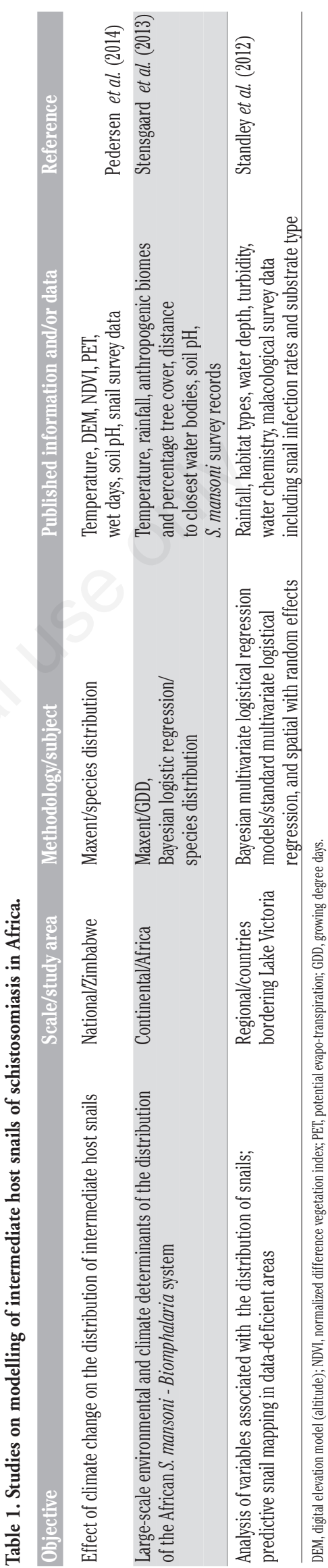




\section{Progress in geo-spatial technology application in schistosomiasis modelling}

Spatial technologies have provided an invaluable analytical tool to better understand the determinants and distribution of schistosome infections in Africa (Figure 1 and Tables 1-3). It is well known that climate and environmental factors determine the distribution of schistosomiasis (Appleton, 1978; Brown, 1994; Brooker, 2002) hence it is restricted in space and time by environmental factors (Rollinson et al., 2001; Malone, 2005). In this regard, spatial technologies are useful in understanding the distribution of parasites and their hosts as depicted in the maps showing the interplay with spatial and temporal features of the environment. The general objective of the models is to link the variables related to schistosomiasis transmission or snails with spatial parameters (Simoonga et al., 2009). Most studies use spatial modelling techniques such as logistic regression (Brooker et al., 2001, 2002b), Maxent (Stensgaard et al., 2013; Pedersen et al., 2014), genetic algorithm for rule-set prediction (GARP) (Stensgaard et al., 2006), generalized linear models (GLMs) and generalised additive models (GAMs) (Pfukenyi et al., 2006). There are also non-regression models such as the Bayesian geostatistical approach for modelling intermediate host snails distribution and prevalence of schistosomiasis (Raso et al., 2005; Vaunatsou et al., 2009; Schur et al., 2013). The use of GIS and remote sensing in these models has contributed towards optimized schistosomiasis control efforts at different spatial scales through identifying vulnerable populations for mass treatment (Brooker, 2007) and permitting more rational allocation of resources for cost-effective control (Beck et $a l ., 1997,2000)$. However, there are limitations with regards the applicability and robustness of these models that compromise their effectiveness in promoting community public health especially at local levels.

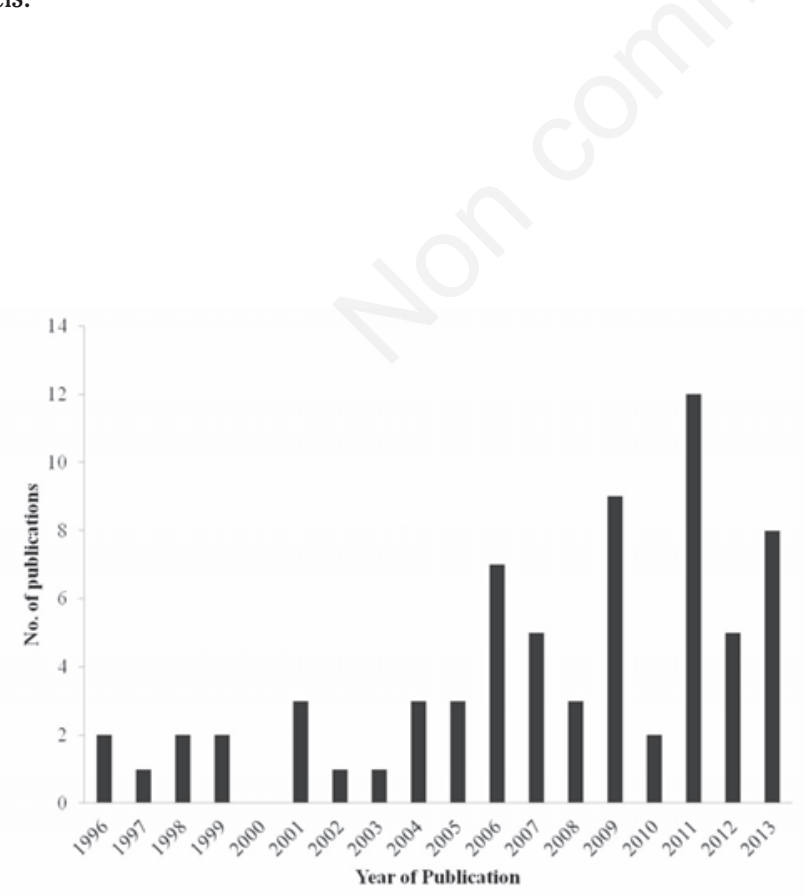

Figure 1. Number of publications pertaining to remote sensing and geographic information system with application to schistosomiasis in Africa from 1996 to 2008 (Simoonga et al., 2009) and 2009 to 2013 (this review).

\section{Geo-spatial technology in schistosomiasis mod- elling: pros and cons}

Earth observation has been providing spatial data (and will continue to do so) for developing GIS models for predicting and mapping the risk of schistosomiasis, mostly in inaccessible regions of Africa and in scenarios involving environmental or climate change. However, there are still challenges which warrant further research and refinements/ improvements (Herbreteau et al., 2007; Simoonga et al., 2009). In the early stages of the development of GIS and remote sensing technology, the main challenge was the possible resistance to the uptake of EO technology mainly attributed to costs of image processing equipment, expertise and subsequent ground validation (Hay, 1997). To date, it might be true that remote sensing has not become the wonder tool as it was expected to be, to echo Herbreteau et al. (2007), mainly because of limited capacity in processing and use of remote sensing data especially in Africa. EO data requires processing and understanding of the purpose for which it is intended without which the output may be as meaningless as the raw data. Therefore the existing schistosomiasis predictive models are weakened by several factors, including statistical uncertainty in variable selection criteria and methods used, low spatial resolution, failure to utilize the temporal aspect of EO data for spatiotemporal prediction of schistosomiasis, limited application of the developed models in different areas as well as uncertainty and lack of vigorous validation as discussed below.

\section{Unjustified variable selection criteria}

The role of non-climatic factors such as topography, distance to water and soil types have been considered in large-scale studies (Tables 1-3). However they have not been given considerable attention compared to climatic factors as determinants of the spatial distribution of schistosomiasis particularly at the local level. These factors could easily be mapped using GIS to determine their influence on schistosomiasis transmission. For example, the distance to water determines

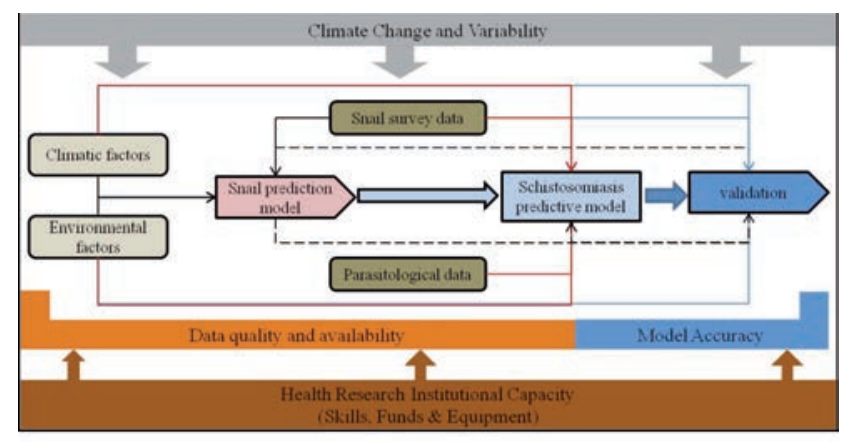

Figure 2. Theoretical framework for a schistosomiasis predictive modelling. 


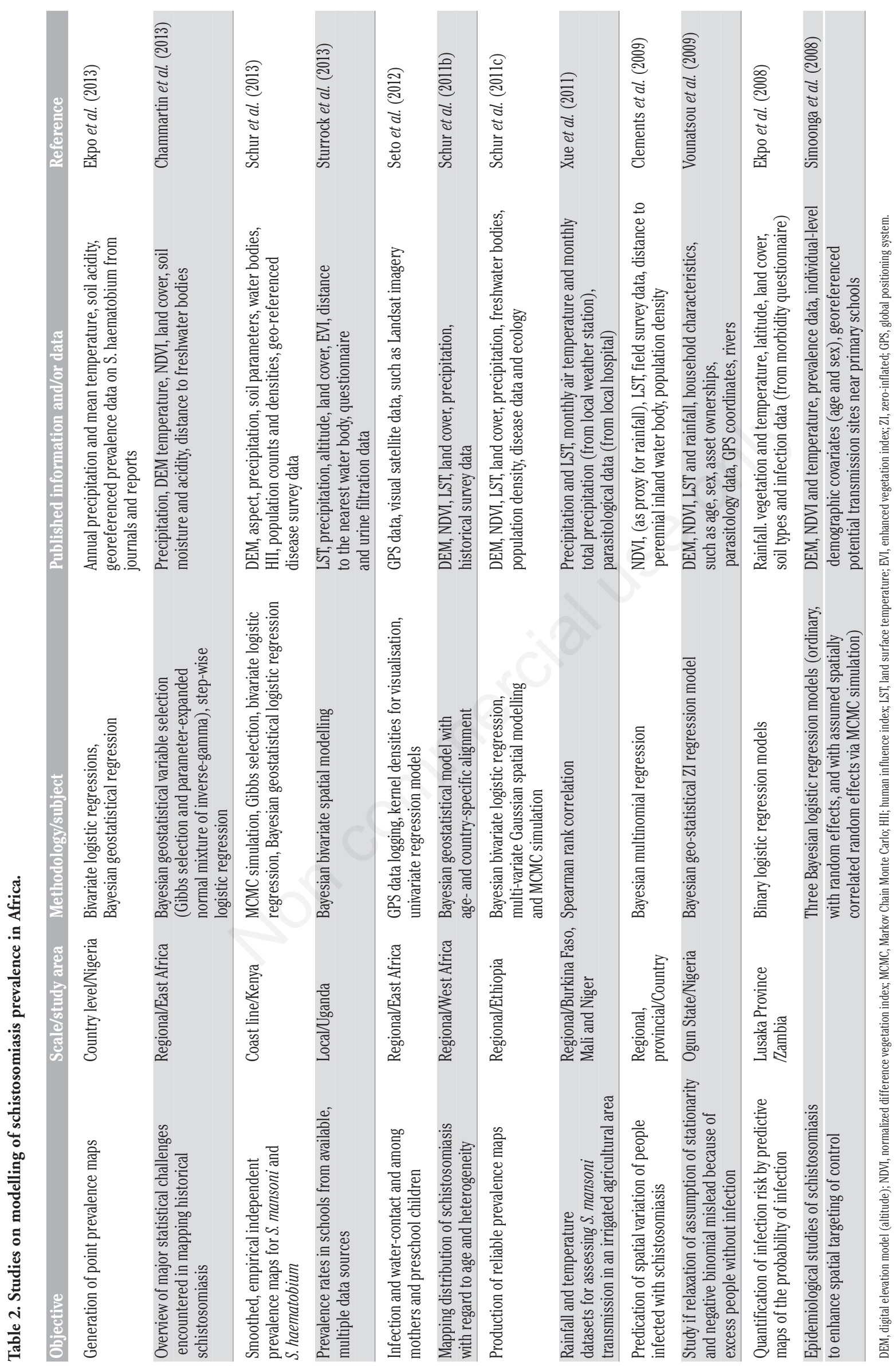




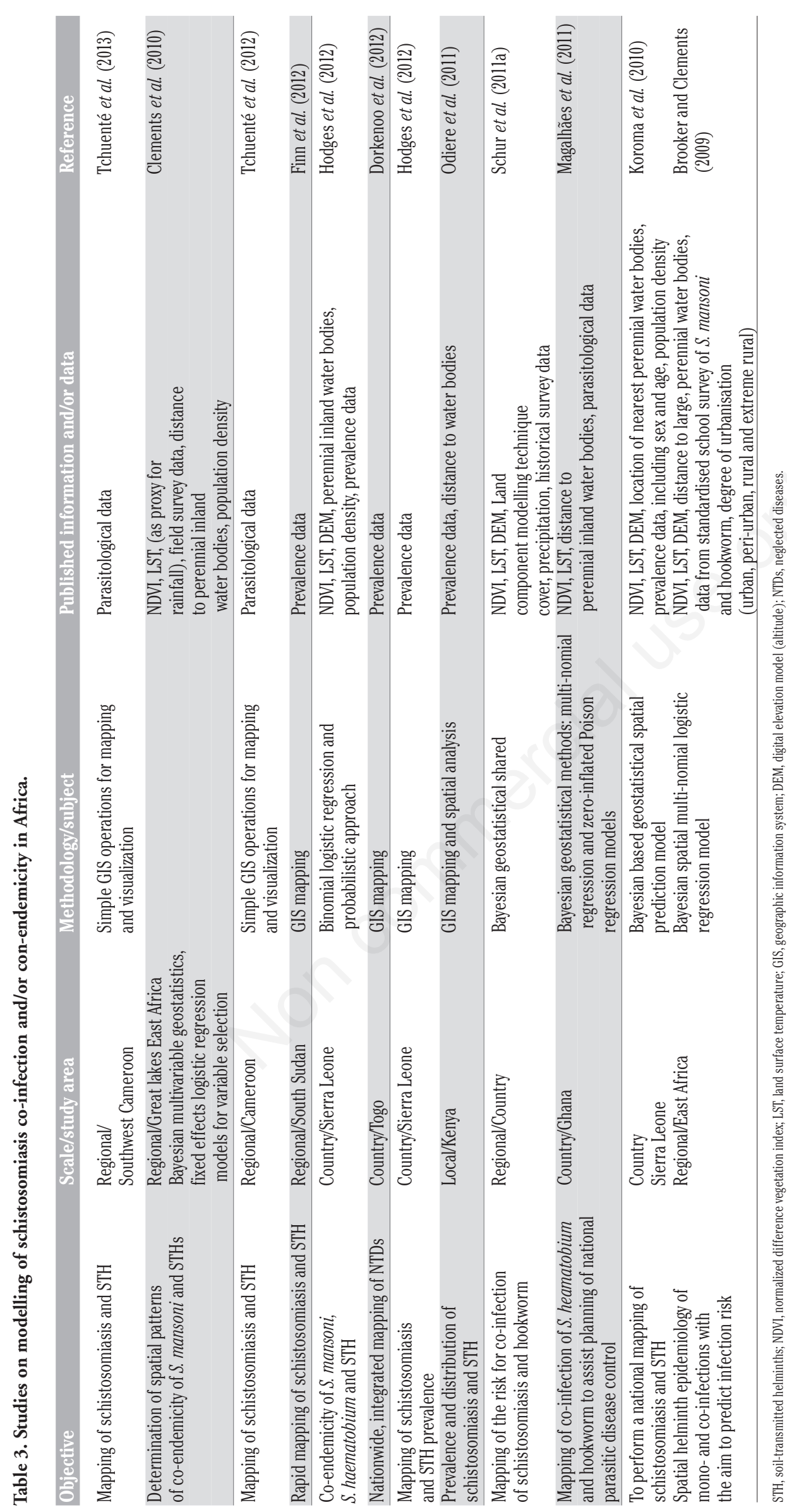


the human water-contact behaviour, which has a strong influence on the prevalence and intensity of schistosomiasis (Stensgaard et al., 2013; Chimbari et al., 2003). Furthermore, studies have shown that Biomphalaria pfeifferi can tolerate a maximum flow speed of up to 0.3 m/s (Appleton, 1978; Kloos et al., 2001) and soil types determine the water-soluble calcium (Ca) and $\mathrm{pH}$ levels. Together, these factors have an effect on the presence and density of snails that ultimately decides the risk for infection. Further, Raso et al. (2005) observed that distance to permanent rivers was significantly associated with $S$. mansoni infection in the non-spatial logistic regression but showed no significant association in spatially explicit models. Saathof et al. (2002) also concluded that most of the environmental factors (slope, distance to water and vegetation cover) inadequately explain the spatial pattern of schistosomiasis infection at the sub-district level except with regard to altitude. Although this is probably true, this assertion still requires further investigation. Moreover, rainfall and temperature were not used in this particular study as the necessary data for that spatial resolution were not available and it was anticipated that the variation within such a small area would have been small (Moodley et al., 2003). Rainfall and normalized difference vegetation index (NDVI) have been widely used as proxies for water availability. In their study, Standley et al. (2012) noted that water availability may be insignificant in the context of permanent large water bodies. However, the significance of these environmental factors may still need to be investigated as they may be proxies for water availability in temporal and spatial modelling of schistosomiasis at the local level.

In their large review, Simoonga et al. (2009) noted that a few researchers have attempted to relate disease prevalence and socio-economic profiles of the local population using GIS applications. Such analyses may be linked to intermediate host snails distribution datasets explained by EO environmental and climatic factors. Schistosomiasis is heterogeneous, so there is need to undertake localised studies to establish exposure risk factors and link water contact patterns with malacological surveys (Simoonga et al., 2008). Schur et al. (2013) used Bayesian modelling and they believe that their model could have performed better if they had included intermediate host snail data. Sturrock et al. (2013) highlighted the need to consider locations of transmission sites and not just distance to water bodies (a river in their case) to improve the performance of their prediction model. Simoonga et al. (2009) reported that socio-economic factors, such as availability of sanitary facilities and safe water supply may better explain different levels of transmission at local-scale than for instance, poverty quintiles as seen in a the micro-level study in Côte d'Ivoire by Raso et al. (2005). Chimbari et al. (2003) attributed differences in schistosomiasis distribution and intensity between Lake Kariba (Zimbabwe) and Siavonga (Zambia) (10 km apart) to different sanitation (better in Lake Kariba) and access to water from the lake (easy access for Siavonga compared to Kariba). Seto et al. (2012) used wearable GPS data-loggers for mapping and assessing the exposure of women and children to risk factors such as access to water. This, however may have influenced behaviour and affecting the performance of the prediction model. This opens avenues for further research as the inclusion of these factors may improve the performance of the model.

\section{Statistical uncertainty}

The use of simple threshold analysis (Malone et al., 2001) or logistic regression (Brooker et al., 2001, 2002a; Ekpo et al., 2008) modelling to predict infection risk are both limited by the inability of these methods to con- sider spatial correlation of infection and environmental variables. This leads to underestimation of standard errors of covariate coefficients resulting in erroneous inference and justifies the need for assessment of uncertainties inherent in data and modelling techniques (Brooker, 2007). Variable selection in predictive modelling is a major challenge due to analytical problems caused by over-fitting, confounding and non-independence of data (Craig et al., 2007). Schistosomiasis transmission predictive models mostly derived from regression models are conservative, because they use only a few (two or three) climate variables to model the disease. While this is simple to understand as required in most models, it could be more reasonable and realistic to include more factors such as the effects of sanitation, water-related activities (Simoonga et al., 2009; Stensgaard et al., 2013), snail presence and absence data (Moodley et al., 2003; Schur et al., 2013). The mapping of infected snails could also help clarify the complex interaction between snail, parasites and the environmental factors that are usually used to predict the distributions (Simoonga et al., 2009). However, the approach requires systematic and repeatable staged variable selection procedures, including spatial analysis to achieve a parsimonious model with the desired level of internal and external validity (Craig et al., 2007). This could be resolved by using the machine-learning algorithms such as Maxent (Stensgaard et al., 2013; Pedersen et al., 2014) and GARP (Stensgaard et al., 2006), which can handle larger number of variables (continuous and categorical) than regression models. Bayesian geostatistical approach has been widely used in schistosomiasis modelling over the seven latest years (Raso et al., 2005; Clements et al., 2006; Vaunatsou et al., 2009; Schur et al., 2011a, 2011b, 2011c; 2013). This approach is regarded as a flexible and robust (Brooker, 2007) that takes into account spatial variability of epidemiological and environmental data as it uses the semivariogram of the spatial process (Chiles and Definer, 1999). However, only a few aspects of geostatistical methods have been explored in schistosomiasis modelling. For example isotropy is more often used than anisotropy (Simoonga et al., 2008; Vaunatsou et al., 2009). Isotropy is independent of location and direction and assumes that spatial correlation is only a function of distance (Gosoniu et al., 2009). This is contrary to anisotropy, which assumes that spatial correlation is a function of distance in relation to both location and direction. It is likely that there is high correlation of intensity and prevalence of schsistosomiasis towards transmission sites (Vaunatsou et al., 2009) and linked to the main flow direction of the river (Beck-Wörner et al., 2007). Schur et al. (2013) applied anisotropy at the regional scale in East Africa and recommend the application of this method at the local scale. These authors emphasise that ignoring anisotropy could influence the strength of association and thus also the spatial range parameter estimates, which might reduce model ability, especially in the presence of strong anisotropy. Most of the studies on geospatial modeling and/or mapping of schistosomiasis at the local scale do not consider coindemicity or co-infection of $S$. mansoni and $S$. haematobium (Gryseels, 1996; Raso et al., 2005; Brooker and Clements, 2009). Advanced geostatistical capabilities, such as shared component modelling (Schur, 2011a) and Bayesian geostatistical multinomial regression modelling (Magalhães et al., 2011), which can model co-infections, have not been fully exploited with reagrd to schistosomiasis co-infections and/or co-endemicity modelling. These techniques allow simultaneous modelling of co-endemicity or co-infection of the two common schistosome species in Africa (S. mansoni and $S$. haematobium) and investigate the independence between the two and how they respond to different climatic and environmental factors. However, the results are affected by inconsistency in data that can be due to different samples, different sample sizes and time of sampling, which may compromise the quality of model outputs (Hodges et al., 2012). This type of inconsistencies can be handled well using geostatistical methods such as shared component modelling as compared to Bayesian geostatistical multinomial regression modeling which can only use data from sur- 
veys screening for multiple infections simultaneously (Schur et al., 2011a). Generally, there is paucity of information on the geographical distribution of both species within co-endemic regions and knowledge of micro-geographical variation of single and mixed schistosoma infections and morbidity. Thus, modelling the two parasites could provide important insights into the drivers of infection and disease, which could help tailoring schistosomiasis control and elimination efforts (Meurs et al., 2013). It is believed that chronic infections cause adverse morbidity-related effects that are exacerbated by infections by multiple species and high parasite loads (Pullan and Brooker, 2008). Modelling schistosome co-infections could make it easier to determine whether these infections impact species-specific morbidity compared to single species infection (Gouvras et al., 2013). To date, the effects of schistosome co-infection on morbidity are not clear (Sang et al., 2014; Meurs et al., 2012) and modelling these coinfections could help targeting specific micro-geographical locations for further research on design of superior intervention strategies.

\section{Low spatial resolution - remote sensing data}

The increasing use of spatial low-resolution imagery (500 m or less) has provided an opportunity to explore the distribution of schistosomiasis at broad scales (country, regional and continental) (Brooker and Michael, 2000; Brooker, 2002; Clennon et al., 2006). Still, however, ineffective schistosomiasis prediction remains a public health concern in geographically restricted areas as low-resolution investigations do not consider local heterogeneity of snails and schistosomiasis (Kitron et al., 2006). The small-scale focality of schistosomiasis is well recognised and the causes of heterogeneity are varied and reflect many human and ecological factors (Kloos et al., 1997, 1998; Woolhouse and Chandiwana, 1989). This makes the small-scale distribution difficult to predict (Brooker, 2002) as the effects of local heterogeneity are averaged out at broader scales and ecological patterns often appear more regular (Wiens, 1989; Levin, 1992). Brooker (2002), emphasized that the use of remote sensing has not been very successful in capturing the well-known local variation of schistosomiasis transmission, for example, the 8-km advanced very high resolution radiometer (AVHRR) used by Brooker et al. (2002a, 2002b) may generalize the spatial variation of schistosomiasis. Although satellite instruments can deliver higher resultion imagery, such as SPOT 5 and 6 (http://www.geoairbusds.com/en/147-spot-6-7-satellite-imagery) and Landsat 8 (http://andsat.usgs.gov/landsat8.php) even most recent African studies are based on low-resolution satellite products from the moderate resolution imaging spectroradiometer (MODIS) (http://modis.gsfc. nasa.gov/) and American National Oceanic and Atmospheric Administration (NOAA) (http:/www.noaa.gov/) AVHRR (Tables 1-3). There is need for the use of high-resolution instruments to capture the local ecological spatial variation of intermediate host snails or prevalence of schistosomiasis (Brooker et al., 2001, 2002a). Indeed, highresultion imagery is available but has only been used occasionly due to the current high cost. For example, the very recent study of De Roeck et al. (2014) on Fasciola hepatica in Belgium using drones and very high resolution (VHR) imagery from the commercial WorldView2 staellite (https://www.digitalglobe.com/sites/default/ files/DG_WorldView2_DS_PROD.pdf) is a case in point. Fine-scale monitoring is of key importance to refine currently existing broad-scale infection risk models, and costs might dimish with time alowing a more widely use of the technology. Generally, however, there is no single natural scale, at which ecological patterns are studied (Levin, 1992). In each case, the appropriate scale is dictated by the goals of the study, system and available data. Hence, there is need for developing remote sensing predictive models for targeting schistosomiasis control at local levels. There is also need to focus on the household as spatial points in high endemic areas instead of schools, as this will help to avoid spatial aggregation and allow appropriate finite scale spatial mapping and give insight into the micro-epidemiology of schistosomiasis (Simoonga et al., 2008).

\section{Failure to utilize the temporal domain of remote sensing}

The temporal characteristic of remote sensing has not been fully utilized in modelling the temporal variation of schistosomiasis in Africa. Brooker (2002) has highlighted that the temporal variation of schistosomiasis has received far too little attention despite its relevance in understanding the spatial distribution of infection. Seasonal and intraseasonal modelling of schistosomiasis may capture the variation of snail density and occurrence as some snails maybe washed away during the rainy season (Appleton, 1978; Kloos et al., 2001) and some may die due to desiccation during the dry season (Rollinson et al., 2001). This may also explain the spatial and temporal variability of point prevalence, infection rate and intensity of schistosomiasis especially at local levels. This emphasizes the relevance of intra-seasonal and seasonal modelling of schistosomiasis in timely allocation of resources as well as targeting of control programs. Most of the schistosomiasis predictive models consider annual distribution of schistosomiasis (Stensgaard et al., 2013; Pedersen et al., 2014) but not the component of seasonality. Considering the temporal resolution of satellite data could help to syncronise the temporal differences between data collection of variables and disease or parasitological data as highlighted by Sturrock et al. (2013). There is need for ecological niche modelling of seasonal vector population dynamics combining ecological niche models with purpose-built, temporal high-resolution satellite remote sensing data (Kulkarni et al., 2010). On the other hand, remote sensing technology has been available for more than 30 years, but only a few studies such as that by Pedersen et al. (2014) have taken up the challenge to model the changes in snail habitats over the past years to estimate the possible distribution of schistosomiasis in relation to climate and environmental changes.

\section{Application limitations}

Brooker (2002) emphasized the need to develop separate models for each snail-schistosome system due to their different habitat types and environmental suitability. Thus, these models are not transferable to other regions or places. This is evident from the work of Malone et al. (2001), who developed a region-specific schistosomiasis predictive model with limited application elsewhere where different ecological conditions and snail species prevail. This compromises the validity of the continental- and regional-level models, advocating the local scale. Until 2009, there was no schisotosmiasis model at a continental level (Simoonga et al., 2009) and, to our knowledge, Stensgaard et al. (2013) is the only study investigating schistosomiasis distribution in Africa as a whole. Simoonga et al. (2009) highlight several challenges that must be overcome in order to further improve the GIS-based mapping of intermediate host snails at the continental scale. Consequently, there is a lack of large-scale, geo-referenced quality data on the presence/ 
absence of snails as well as parasite-snail compatibilities. There is also need for a more complete understanding of snail species identities and their efficiencies as intermediate hosts as prescribed by Stothard et al. (2002). The challenge is to develop a composite risk map of schistosomiasis (Brooker, 2002), which could be achieved through shared component modelling technique as highlighted above.

\section{Lack of vigorous validation or accuracy assessment}

An important but often difficult part of a disease model is the assessment of applicability and validity, especially if outputs are to be used for disease control. The quality of predictive (presence or absence) models of a species is normally judged by the number of prediction errors or its accuracy (Fielding and Bell, 1997). Accuracy refers to the correctness of remotely sensed data or model outputs, which measures the agreement between a standard assumed to be the correct and classified image or the result of a model of unknown quality (Foody, 2001; Campbell, 2006). Despite the wide use of predictive models, most applications do not give sufficient consideration to model error and uncertainty (Barry and Elith, 2006). Datasets used to statistically develop the models are often of uncertain accuracy and are not always easily reproducible as the results vary with training data and methods used (Tanser et al., 2003). These generic disadvantages vary from worldwide or continent-wide (Stensgaard et al., 2013) to regional (Schur et al., 2011a, 2011b, 2011c) statistically-driven models; the models are too coarse to guide intervention efforts and their capacity to predict prevalence remains uncertain (Kulkarni et al., 2010).

Evaluating the predictive models is a crucial step for determining its suitability for specific applications (Guisan and Hofer, 2003; Allouche et al., 2006). In this case, the focus is on schistosomiasis control and the possibility of comparing with other models and classification techniques (Powell et al., 2004). Any approach to ecological modelling has little merit if predictions cannot be assessed (Verbyla and Litvaitis, 1989) and any maps or satellite products or models without associated accuracy remain untested hypotheses (Strahler et al., 2006). The most commonly used statistical measures of error of predictive models include error matrix (Morisette et al., 2005), the Cohen Kappa statistics, the threshold-independent receiver operating characteristic (ROC) approach (Fielding and Bell, 1997) achieved by calculating the area under the ROC curve (AUC), a Gini coefficient AUC (Copas, 1999), the true skill statistic (TSS) (McPherson et al., 2004), Cohen's Kappa z-test and MacNemar's test. Most of the studies use EO and disease data for schistosomiasis predictive modelling from electronic databases and only a few models for example Schur et al. (2011a, 2011b, 2011c, 2013) have been adequately evaluated and provided with proper statistical quantification of error. The main constraint in validation is lack of updated, comprehensive, good quality empirical data (Moodley et al., 2003; Tanser et al., 2003). This has compromised the quality, applicability and reliability of the developed models. The maps representing the world-wide or country-wide burden of schistosomiasis generally reflect the reported distribution of clinical episodes of this disease. However, the scope and accuracy of such reports are limited by the extent of health care coverage, the efficacy of surveillance and also by the quality of the reporting systems (Kiszewski et al., 2004). This paucity of epidemiological data hinders large-scale quantification of the burden of a disease (Brooker et al., 2002a, 2002b).

\section{Potential future research priorities}

Availability of affordable treatment of schistosomiasis (praziquantel) has led to increased interest and commitment to effective and efficient control of this disease. However, control resources are inevitably limited, necessitating predictive models that can rapidly and accurately identify and map high-risk communities so that interventions can be targeted in a spatially-explicit and cost-effective manner (Brooker, 2009). Geospatial technologies are promising with respect to meeting this objective. However, disease data, climatic and environmental data must not only be reliable, but also be possible to collect at suitable spatial and temporal resolutions. Figure 2 illustrates the proposed theoretical framework for schistosomiasis predictive modeling considering four phases; data collection, snail prediction modeling, schistosomiasis predictive modeling and validation which are based on data quality and availability as well as model accuracy. The whole system is sustained by health research institutional capacity in terms of skills, funds and equipment to generate high quality data and achieve desirable predictive model accuracy (Figure 2).

Although remote sensing has proved to be a reliable source of climatic and environmental data, there is need to consider satellites with higher spatial resolution such as SPOT-6 as opposed to low spatial resolution imagery of 1 and $8 \mathrm{~km}$ for MODIS and AVHRR, respectively, while ultrahigh-resultion imagry will have to wait until cost dimishes. The E0 technology could offer higher spatial and spectral, more frequent coverage and lower cost data as suggested by Lleo et al. (2008), however, specialized skills and expertise are a pre-requisite so as to realize the full advantages of these developments. Mostly, E0 data are developed for a wide range of applications and epidemiologists have to develop specific products or applications for specific purposes rather than relying on already processed or off-shelf products such as the normalized difference vegetation index (NDVI) and land surface temperature (LST) with no metadata. These products may have been developed for different purposes at different scales and may not serve the same purpose with same level of accuracy required in schistosomiasis modelling. This indicates the need for investing more time and resources in the development, application and use of the space technology in epidemiology.

Field studies will still be needed to generate high quality data including climatic and environmental factors for calibration of EO data as shown in Figure 1. The output predictive models should also be validated against field observations as argued by Bergquist et al. (2009) to realize their usefulness in community health and climate change decision making process especially at the local level in Africa. This will help to capture the local focality of schistosomiaisis as the use of high quality and reliable data could help to refine the geostatistical techniques and adoption of ecological tools such as Maxent (Phillips et al., 2006), which are promising to produce highly performing schistosomiasis predictive models (Stensgaard et al., 2013). The field measured data could also be complemented by laboratory experiments as the behavior of snails and schistosome parasites could change due to climatic and environmental changes. For example Brown (1994) studied the distribution of freshwater host snails in Africa and divided them into two groups (tropical and temperate species) based on the climate where they occur. However the snail species tolerance ranges for temperature might have changed over time, which requires more field studies for verification and comparison. On the other hand, systematic field studies on the relationship between densities and infection rates in snails and those in humans would still be highly useful (Gryseels, 1996). The rational use of remote sensing data is dependent of the quality of infor- 
mation from the field (De la Rocque et al., 2005), which requires sophisticated geo-spatial statistical methods for analysis and predictive modeling and dedicated fieldwork to validate the observations (Herbreteau et al., 2005). Hence, the need for interdisciplinary approach in which epidemiologists collaborate with software programmers, geographers and spatial analysts to create robust techniques and products for use with epidemiological data (Jacquez, 2000; Graham et al., 2004; Herbreteau et al., 2007).

\section{Conclusions}

Geo-spatial technologies are invaluable for schistosomiasis mapping and transmission prediction, particularly in Africa. However, more extensive applications of these tools have been hampered by lack of training, gaps in data (quality and quantity, particularly climatic, environmental, epidemiologic and parasitologic data) and inadequate tools for data gathering (Hay, 2000). These are clear indications of possible sources of errors and uncertainties that have propagated the schistosomiasis transmission modelling in Africa. Therefore, Herbreteau et al. (2007) is correct in saying that major elements of geospatial technologies have not yet met our current needs. However, in China, Yang et al. (2005) viewed future prospects of GIS and remote sensing application in disease mapping as bright and promising; hence, it might be too early to blame the technology. Instead, there is need to take advantage and sharpen ideas and skills to develop more and better methods through further research and refinement of the schistosomiasis predictive models to meet community needs. This could be achieved through collaboration between epidemiologists, geographers and software programmers, use of high-quality remote sensing and ground measured data and thorough validation protocols. It would also allow the adoption and use of some tools developed in ecology such as Maxent and GARP machine-learning algorithms and refining geostatistical techniques for predictive modelling of schistosomiasis at the local level.

\section{References}

Allouche 0, Tsoar A, Kadmon R, 2006. Assessing the accuracy of species distribution models: prevalence, kappa and the true skill statistic. J Appl Ecol 43:1223-32.

Appleton CC, 1978. Review of literature on abiotic factors influencing the distribution and life-cycles of bilharziasis intermediate host snails. Malacolo Rev 11:1-25.

Barry SC, Elith J, 2006. Error and uncertainty in habitat models. J Appl Ecol 43:413-23.

Beck LR, Lobitz BM, Wood BL, 2000. Remote sensing and human health: newsensors and new opportunities. Emerg Infect Dis 6:21727.

Beck LR, Rodriguez MH, Dister SW, Rodriguez AD, Washino RK, Roberts DR, Spanner MA, 1997. Assessment of a remote sensing based model for predicting malaria transmission risk in villages of Chiapas, Mexico. Am J Trop Med Hyg 56:99-106.

Beck-W rner C, Raso G, Vounatsou P, N'Goran EK, Rigo G, Parlow E, Utzinger J, 2007. Bayesian spatial risk prediction of Schistosoma mansoni infection in western Cote d'Ivoire using a remotelysensed digital elevation model. Am J Trop Med Hyg 76:956-63.

Bergquist R, Johansen MV, Utzinger J, 2009. Diagnostic dilemmas in helminthology: what tools to use and when? Trends Parasitol 25:151-6.

Brooker S, 2002. Schistosomes, snails and satellites. Acta Trop 82:20714.

Brooker S, 2007. Spatial epidemiology of human schistosomiasis in Africa: risk models, transmission dynamics and control. T Roy Soc Trop Med H 101:1-8.

Brooker S, Clements AC, 2009. Spatial heterogeneity of parasite coinfection: determinants and geostatistical prediction at regional scales. Int J Parasitol 39:591-7.

Brooker S, Michael E, 2000. The potential of geographical information systems and remote sensing in the epidemiology and control of human helminth infections. Adv Parasit 47:245-88.

Brooker S, Hay SI, Bundy DA, 2002a. Tools from ecology: useful for evaluating infection risk models? Trends Parasitol 18:70-4.

Brooker S, Hay SI, Issae W, Hall A, Kihamia CM, Lwambo NJS, Wint W, Rogers DJ, Bundy DAP, 2001. Predicting the distribution of urinary schistosomiasis in Tanzania using satellite sensor data. Trop Med Int Health 6:998-1007.

Brooker S, Hay SI, Tchuem Tchuente LA, Ratard R, 2002b. Using NOAAAVHRR data to model human helminth distributions in planning disease control in Cameroon, West Africa. Photogramm Eng Rem S 68:175-9.

Brown DS, 1994. Freshwater snails of Africa and their medical importance. Taylor \& Francis, London, UK.

Campbell JB, 2006. Introduction to remote sensing. The Guilford Press, New York, NY, USA.

Chammartin F, Hürlimann E, Raso G, N'Goran EK, Utzinger J, Vounatsou P, 2013. Statistical methodological issues in mapping historical schistosomiasis survey data. Acta Trop 128:345-52.

Chiles JP, Delfiner P, 1999. Geostatistics. Wiley, New York, NY, USA.

Chimbari MJ, Dhlomo E, Mwadiwa E, Mubila L, 2003. Transmission of schistosomiasis in Kariba, Zimbabwe, and a cross-sectional comparison of schistosomiasis prevalences and intensities in the town with those in Siavonga in Zambia. Ann Trop Med Parasit 97:605-16.

Chitsulo L, Engels D, Montresor A, Savioli L, 2000. The global status of schistosomiasis and its control. Acta Trop 77:41-51.

Clements AC, Deville MA, Ndayishimiye 0, Brooker S, Fenwick A, 2010. Spatial co distribution of neglected tropical diseases in the East African Great Lakes region: revisiting the justification for integrated control. Trop Med Int Health 15:198.

Clements AC, Firth S, Dembelé R, Garba A, Touré S, Sacko M, Landouré A, Bosqué-Oliva E, Barnett AG, Brooker S, Fenwick A, 2009. Use of Bayesian geostatistical prediction to estimate local variations in Schistosoma haematobium infection in western Africa. B World Health Organ 87:921-9.

Clements AC, Moyeed R, Brooker S, 2006. Bayesian geostatistical prediction of the intensity of infection with Schistosoma mansoni in East Africa. Parasitology 133:711-9.

Clennon JA, Mungai PL, Muchiri EM, King CH, Kitron U, 2006. Spatial and temporal variations in local transmission of Schistosoma haematobium in Msambweni, Kenya. Am J Trop Med Hyg 75:103441.

Copas J, 1999. The effectiveness of risk scores: the logit rank lot. Appl Stat 48:165-83.

Craig MH, Sharp BL, Mabaso ML, Kleinschmidt I, 2007. Developing a spatial-statistical model and map of historical malaria prevalence in Botswana using a staged variable selection procedure. Int $\mathrm{J}$ Health Geogr 6:44.

de La Rocque S, Michel JF, Bouyer J, De Wispelaere G, Cuisance D, 2005. Geographical information systems in parasitology: a review 
of potential applications using the example of animal trypanosomosis in West Africa. Parassitologia 47:97-104.

De Roeck E, Van Coillie F, De Wulf R, Soenen K, Charlier J, Vercruysse J, Hantson W, Ducheyne E, Hendrickx G, 2014. Fine-scale mapping of vector habitats using very high resolution satellite imagery: a liver fluke case-study. Geospatial Health 8:671-83.

Despommier DD, Gwadz RW, Hotez PJ, 1994. Parasitic diseases. Springer-Verlag, New York, NY, USA.

Dorkenoo AM, Bronzan RN, Ayena KD, Anthony G, Agbo YM, Sognikin KSE, Dogbe KS, Amza A, Sodahlon Y, Mathieu E, 2012. Nationwide integrated mapping of three neglected tropical diseases in Togo: countrywide implementation of a novel approach. Trop Med Int Health 17:896-903.

Ekpo UF, Hürlimann E, Schur N, Oluwole AS, Abe EM, Mafe MA, Nebe OJ, Isiyaku S, Olamiju F, Kadiri M, Poopola TOS, Braide EI, Saka Y, Mafiana CF, Kristensen TK, Utzinger J, Vounatsou P, 2013. Mapping and prediction of schistosomiasis in Nigeria using compiled survey data and Bayesian geospatial modelling. Geospatial Health 7:355-66.

Ekpo UF, Mafiana CF, Adeofun C0, Solarin AR, Idowu AB, 2008. Geographical information system and predictive risk maps of urinary schistosomiasis in Ogun State, Nigeria. BMC Infect Dis 8:74.

Fenwick A, Webster JP, Bosque-Oliva E, Blair L, Fleming FM, Zhang Y, Garba A, Stothard JR, Gabrielli AF, Clements ACA, Kabatereine NB, Toure S, Dembele R, Nyandindi U, Mwansa J, Koukounari A, 2009. The Schistosomiasis Control Initiative (SCI): rationale, development and implementation from 2002-2008. Parasitology 136:171930.

Fielding AH, Bell JF, 1997. A review of methods for the assessment of prediction errors in conservation presence/absence models. Environ Conserv 24:38-49.

Finn TP, Stewart BT, Reid HL, Petty N, Sabasio A, Oguttu D, Lado M, Brooker SJ, Kolaczinski JH, 2012. Integrated rapid mapping of neglected tropical diseases in three states of South Sudan: survey findings and treatment needs. PloS 0ne 7:e52789.

Foody GM, 2001. Progress reports, GIS: the accuracy of spatial data revisited. Prog Phys Geogr 25:289-398.

Gosoniu L, Vounatsou P, Sogoba N, Maire N, Smith T, 2009. Mapping malaria risk in West Africa using a Bayesian nonparametric nonstationary model. Comput Stat Data An 53:3358-71.

Gouvras AN, Kariuki C, Koukounari A, Norton AJ, Lange CN, Ireri E, Fenwick A, Mkoji GM, Webster JP, 2013. The impact of single versus mixed Schistosoma haematobium and S. mansoni infections on morbidity profiles amongst school-children in Taveta, Kenya. Acta Trop 128:309-17.

Graham AJ, Atkinson PM, Danson FM, 2004. Spatial analysis for epidemiology. Acta Trop 91:219-25.

Gryseels B, 1996. Uncertainties in the epidemiology and control of schistosomiasis. Am J Trop Med Hyg 103-08.

Guisan A, Hofer U, 2003. Predicting reptile distributions at the mesoscale: relation to climate and topography. J Biogeogr 30:123343.

Hay SI, 1997. Remote sensing and diseases control: past present and future. T Royal Soc Trop Med H 91:105-6.

Hay SI, 2000. An overview of remote sensing and geodesy for epidemiology and public health application. Adv Parasit 47:1-35.

Herbreteau V, Salem G, Souris M, Hugot JP, Gonzalez JP, 2005. Sizing up human health through remote sensing: uses and misuses. Parassitologia 47:63-79.

Herbreteau V, Salem G, Souris M, Hugot JP, Gonzalez JP, 2007. Thirty years of use and improvement of remote sensing, applied to epi- demiology: from early promises to lasting frustration. Health and Place 13:400-3.

Hodges MH, Magalhães RJS, Paye J, Koroma JB, Sonnie M, Clements A, Zhang Y, 2012. Combined spatial prediction of schistosomiasis and soil-transmitted helminthiasis in Sierra Leone: a tool for integrated disease control. PLoS Neglect Trop D 6:e1694.

Hürlimann E, Schur N, Boutsika K, Stensgaard AS, Laserna de Himpsl M, Ziegelbauer K, Laizer N, Camenzind L, Di Pasquale A, Ekpo UF, Simoonga C, Mushinge G, Saarnak CFL, Utzinger J, Kristensen TK, Vounatsou P, 2011. Toward an open-access global database for mapping, control, and surveillance of neglected tropical diseases. PLoS Neglect Trop D 5:e1404.

Jacquez GM, 2000. Spatial analysis in epidemiology: nascent science or a failure of GIS? J Geogr Syst 2:91-7.

King $\mathrm{CH}, 2009$. Toward the elimination of schistosomiasis. New Engl $\mathrm{J}$ Med 360:106-9.

King CH, Sturrock RF, Kariuki HC, Hamburger J, 2006. Transmission control for schistosomiasis - why it matters now. Trends Parasitol 22:575-82.

Kiszewski A, Mellinger A, Spielman A, Malaney P, Sachs SE, Sachs J, 2004. A global index representing the stability of malaria transmission. Am J Trop Med Hyg 70:486-8.

Kitron U, Clennon JA, Cecere MC, Gurtler RE, King CH, VazquezProkopec G, 2006. Upscale or downscale: applications of fine scale remotely sensed data to Chagas disease in Argentina and schistosomiasis in Kenya. Geospatial Health 1:49-58.

Kloos H, Fulford AJ, Butterworth AE, Sturrock RF, Ouma JH, Kariuki HC, Thiongo FW, Dalton PR, Klumpp RK, 1997. Spatial patterns of human water contact and Schistosoma mansoni transmission and infection in four rural areas in Machakos District, Kenya. Social Sci Med 44:949-68.

Kloos H, Gazzinelli A, van Zuyle P, 1998. Microgeographical patterns of schistosomiasis and water contact behaviour: examples from Africa and Brazil. Mem I Oswaldo Cruz 93:37-50.

Kloos H, Souza CD, Gazzinelli A, Soares Filho BS, Temba PDC, Bethony J, Kristen PK, Grzywacz C, Lewis F, Minchella D, LoVerd P, Oliveira RC, 2001. The distribution of Biomphalaria spp. in different habitats in relation to physical, biological, water contact and cognitive factors in a rural area in Minas Gerais, Brazil. Mem I Oswaldo Cruz 96:57-66.

Koroma JB, Peterson J, Gbakima AA, Nylander FE, Sahr F, Magalhães RJS., Zhang Y, Hodges MH, 2010. Geographical distribution of intestinal schistosomiasis and soil-transmitted helminthiasis and preventive chemotherapy strategies in Sierra Leone. PLoS Neglect Trop D 4:e891.

Kulkarni MA, Desrochers RE, Kerr JT, 2010. High resolution niche models of malaria vectors in Northern Tanzania: a new capacity to predict malaria risk? PLoS One 5:e9396.

Levin SA, 1992. The problem of pattern and scale in ecology. Ecology 73:1943-67.

Lleo MM, Lafaye M, Guell A, 2008. Application of space technologies to the surveillance and modelling of waterborne diseases. Curr Opin Biotech 19:307-12.

Magalhães RJS, Biritwum NK, Gyapong J0, Brooker S, Zhang Y, Blair L, Fenwick A, Clements AC, 2011. Mapping helminth co-infection and co-intensity: geostatistical prediction in Ghana. PLoS Neglect Trop D 5:e1200.

Malone JB, 2005. Biology-based mapping of vector-borne parasites by geographic information systems and remote sensing. Parassitologia 47:27-50.

Malone JB, Yilma JM, McCarroll JC, Erko B, Mukaratirwa S, Zhou XY, 
2001. Satellite climatology and environmental risk of Schistosoma mansoni in Ethiopia and East Africa. Acta Trop 79:59-72.

McPherson JANA, Jetz W, Rogers DJ, 2004. The effects of species' range sizes on the accuracy of distribution models: ecological phenomenon or statistical artefact? J Appl Ecol 41:811-23.

Meurs L, Mbow M, Boon N, Van den Broeck F, Vereecken K, Dièye TN, Abatih E, Mboup THS, Polman K, 2013. Micro-geographical heterogeneity in Schistosoma mansoni and $S$. haematobium infection and morbidity in a co-endemic community in Northern Senegal. PLoS Neglect Trop D 7:e2608.

Meurs L, Mbow M, Vereecken K, Menten J, Mboup S, Polman K, 2012. Bladder morbidity and hepatic fibrosis in mixed Schistosoma haematobium and $S$. mansoni infections: a population-wide study in Northern Senegal. PLoS Neglect Trop D 6:e1829.

Midzi N, Mduluza T, Chimbari MJ, Tshuma C, Charimari L, Mhlanga G, Manangazira P, Munyati SM, Phiri I, Susan L, Mutambu SL, Midzi SS, Ncube A, Muranzi LP, Rusakaniko S, Mutapi F, 2014. Distribution of Schistosomiasis and soil transmitted Helminthiasis in Zimbabwe: towards a national plan of action for control and elimination. PLoS Neglect Trop D 8:e3014.

Moodley I, Kleinschmidt I, Sharp B, Craig M, Appleton C, 2003. Temperature-suitability maps for schistosomiasis in South Africa. Ann Trop Med Parasit 97:617-27.

Morisette JT, Giglio L, Csiszar I, Justice CO, 2005. Validation of the MODIS active fire products over Southern Africa with ASTER data. Int J Remote Sens 26:4239-64.

Odiere MR, Opisa S, Odhiambo G, Jura WG, Ayisi JM, Karanja D, Mwinzi PN, 2011. Geographical distribution of schistosomiasis and soil-transmitted helminths among school children in informal settlements in Kisumu City, Western Kenya. Parasitology 138:1569-77.

Pedersen UB, Midzi N, Mduluza T, Soko W, Stensgaard A, Vennervald BJ, Mukaratirwa S, Kristensen TK, 2014. Modelling spatial distribution of snails transmitting parasitic worms with importance to human and animal health and analysis of distributional changes in relation to climate. Geospatial Health 8:335-43.

Pfukenyi DM, Mukaratirwa S, Willingham AL, Monrad J, 2006. Epidemiological studies of Schistosoma mattheei infections in cattle in the highveld and lowveld communal grazing areas of Zimbabwe. Onderstepoort J Vet 73:179-91.

Phillips SJ, Anderson RP, Schapire RE, 2006. Maximum entropy modelling of species geographic distributions. Ecol Model 190:231-59.

Powell RL, Matzke N, de Souza C, Clark M, Numata I, Hess LL, Roberts DA, 2004. Sources of error in accuracy assessment of thematic land-cover maps in the Brazilian Amazon. Remote Sens Environ 90:221-34.

Pullan R, Brooker S, 2008. The health impact of polyparasitism in humans: are we under-estimating the burden of parasitic diseases? Parasitology 135:783-94.

Raso G, Matthys B, N'Goran EK, Tanner M, Vounatsou P, Utzinger J, 2005. Spatial risk prediction and mapping of Schistosoma mansoni infections among schoolchildren living in western Cote d'Ivoire. Parasitology 131:97-108.

Rollinson D, Stothard JR, Southgate VR, 2001. Interactions between intermediate snail hosts of the genus Bulinus and schistosomes of the Schistosoma haematobium group. Parasitology 123:245-60.

Saathof E, Olsen A, Kristensen TK, Appleton CC, Sharp B, Kleinschmidt I, 2002. Environmental factors and $S$. haematobium infection in schoolchildren from rural northern KwaZulu-Natal/South Africa. In: Saathof E, ed. Geohelminth and Schistosoma haematobium injection in schoolchildren from rural northern KwaZuluNatallSouth Africa. PhD thesis. Danish Bilharziasis Laboratory \&
University of Copenhagen, Charlottenlund and Copenhagen, Denmark.

Sang HC, Muchiri G, Ombok M, Odiere MR, Mwinzi PN, 2014. Schistosoma haematobium hotspots in south Nyanza, western Kenya: prevalence, distribution and co-endemicity with Schistosoma mansoni and soil-transmitted helminths. Parasite Vector 7:125.

Schur N, Gosoniu L, Raso G, Utzinger J, Vounatsou P, 2011a. Modelling the geographical distribution of co infection risk from single disease surveys. Statistics Med 30:1761-76.

Schur N, Hürlimann E, Garba A, Traoré MS, Ndir 0, Ratard RC, Tchuenté LAT, Kristensen TK, Utzinger J, Vounatsou P, 2011c. Geostatistical model-based estimates of schistosomiasis prevalence among individuals aged $\leq 20$ years in West Africa. PLoS Neglect Trop D 5:e1194.

Schur N, Hürlimann E, Stensgaard AS, Chimfwembe K, Mushinge G, Simoonga C, Kabatereineh NB, Kristensene TK, Utzinger J, Vounatsou P, 2013. Spatially explicit Schistosoma infection risk in eastern Africa using Bayesiangeostatistical modelling. Acta Trop 128:365-77.

Schur N, Utzinger J, Vounatsou P, 2011b. Modelling age-heterogeneous Schistosoma haematobium and S. mansoni survey data via alignment factors. Parasite Vectors 4:1-10.

Seto EY, Sousa-Figueiredo JC, Betson M, Byalero C, Kabatereine NB, Stothard JR, 2012. Patterns of intestinal schistosomiasis among mothers and young children from Lake Albert, Uganda: water contact and social networks inferred from wearable global positioning system dataloggers. Geospatial Health 7:1-13.

Simoonga C, Kazembe LN, Kristensen TK, Olsen A, Appleton CC, Mubita P, Mubila L, 2008. The epidemiology and small-scale spatial heterogeneity of urinary schistosomiasis in Lusaka province, Zambia. Geospatial Health 3:57-67.

Simoonga C, Utzinger J, Brooker S, Vounatsou P, Appleton CC, Stensgaard AS, Olsen A, Kristensen TK, 2009. Remote sensing, geographical information system and spatial analysis for schistosomiasis epidemiology and ecology in Africa. Parasitology 136:168393.

Standley CJ, Vounatsou P, Gosoniu L, Jørgensen A, Adriko M, Lwambo NJ, Lange CN, Kabatereine NB, Stothard JR, 2012. The distribution of Biomphalaria (Gastropoda: Planorbidae) in Lake Victoria with ecological and spatial predictions using Bayesian modelling. Hydrobiologia 683:249-64.

Steinmann P, Keiser J, Bos R, Tanner M, Utzinger J, 2006. Schistosomiasis and water resources development: systematic review, meta-analysis, and estimates of people at risk. Lancet Infect Dis 6:411-25.

Stensgaard A, Jorgensen A, Kabatereine NB, Malone JB, Kristensen TK, 2005. Modelling the distribution of Schistosoma mansoni and host snails in Uganda using satellite sensor data and geographical information systems. Parassitologia 47:115-25.

Stensgaard A, Jorgensen A, Kabatereine NB, Rahbek C, Kristensen TK, 2006. Modelling freshwater snail habitat suitability and areas of potential snail-borne disease transmission in Uganda. Geospatial Health 1:93-104.

Stensgaard A, Utzinger J, Vounatsou P, Hürlimann E, Schur N, Saarnak CF, Simoonga C, Mubita P, Kabatereine NB, Tchuenté LAT, Rahbek C, Kristensen TK, 2013. Large-scale determinants of intestinal schistosomiasis and intermediate host snail distribution across Africa: does climate matter? Acta Trop 128:378-90.

Stothard JR, Mgeni AF, Khamis S, Kristensen TK, Hubbard SJ, Seto E, Ramsan M, Rollinson D, 2002. New insights into the transmission 
biology of urinary schistosomiasis in Zanzibar. T Roy Soc Trop Med H 96:470-5.

Strahler AH, Boschetti L, Foody GM, Friedl MA, Hansen MC, Herold M, Mayaux P, Morisette JT, Stehman SV, Woodcock CE, 2006. Global land cover validation: recommendations for evaluation and accuracy assessment of global land cover maps. Office for Official Publications of the European Communities European Communities, Luxembourg.

Sturrock HJ, Pullan RL, Kihara JH, Mwandawiro C, Brooker SJ, 2013. The use of bivariate spatial modeling of questionnaire and parasitology data to predict the distribution of Schistosoma haematobium in Coastal Kenya. PLoS Neglect Trop D 7:e2016.

Tanser FC, Sharp B, le Sueur D, 2003. Potential effect of climate change on malaria transmission in Africa. Lancet 362:1792-8.

Tchuenté LAT, Ngassam RIK, Sumo L, Ngassam P, Noumedem CD, Nzu DDOL, Dankoni E, Kenfack CM, Gipwe NF, Akame J, Tarini A, Zhang Y, Angwafo III FF, 2012. Mapping of schistosomiasis and soiltransmitted helminthiasis in the regions of Centre, East and West Cameroon. PLoS Neglect Trop D 6:e1553.

Tchuenté LAT, Noumedem CD, Ngassam P, Kenfack CM, Gipwe NF, Dankoni E, Tarini A, Zhang Y, 2013. Mapping of schistosomiasis and soil-transmitted helminthiasis in the regions of Littoral, North-West, South and South-West Cameroon and recommendations for treatment. BMC Infect Dis 13:602.

Utzinger J, Raso G, Brooker S, De Savigny D, Tanner M, Ørnbjerg N, Singer Bh, N'goran Ek, 2009. Schistosomiasis and neglected tropi- cal diseases: towards integrated and sustainable control and a word of caution. Parasitology 136:1859-74.

Verbyla DL, Litvaitis JA, 1989. Resampling methods for evaluating class accuracy of wildlife habitat models. Environ Manage 13:783-7.

Vounatsou P, Raso G, Tanner M, N'Goran EK, Utzinger J, 2009. Bayesian geostatistical modelling for mapping schistosomiasis transmission. Parasitology 136:1695-705.

WHO, 2002. Prevention and control of schistosomiasis and soil-transmitted helminthiasis. First report of the joint WHO expert committees. WHO Tech Rep Ser 912:1-57.

WHO, 2014. Schistosomiasis: a major public health problem. Available from: http:/www.who.int/schistosomiasis/en/

Wiens JA, 1989. Spatial scaling in ecology. Funct Ecol 3:385-97.

Woolhouse MEJ, Chandiwana SK, 1989. Spatial and temporal heterogeneity in the population dynamics of Bulinus globosus and Biomphalaria pfeifferi and the epidemiology of their infection with schistosomes. Parasitology 98:21-34.

Xue Z, Gebremichael M, Ahmad, R, Weldu ML, Bagtzoglou AC, 2011. Impact of temperature and precipitation on propagation of intestinal schistosomiasis in an irrigated region in Ethiopia: suitability of satellite datasets. Trop Med Intl Health 16:1104-11.

Yang GJ, Vounatsou P, Zhou XN, Utzinger J, Tanner M, 2005. A review of geographic information system and remote sensing with applications to the epidemiology and control of schistosomiasis in China. Acta Trop 96:117-29. 